\title{
The Conceptual Design of Dynamic Acoustic Maps to Assess Noise Exposure
}

\author{
Bartłomiej Borkowski ${ }^{1 *}$, Ireneusz Czajka², \\ Marek Pluta ${ }^{1}$, Katarzyna Suder-Dębska ${ }^{2}$ \\ AGH University of Science and Technology, \\ ${ }^{1}$ Department of Mechanics and Vibroacoustics, \\ ${ }^{2}$ Department of Power Systems and Environmental Protection Facilities, \\ 30 Mickiewicza Av., 30-059 Kraków, Poland
}

Received: 3 March 2015

Accepted: 7 March 2016

\begin{abstract}
This paper presents the conceptual design of tools integration for the dynamic creation of sound level distribution maps (acoustic maps) in a production hall with an employee position identification system. This solution allows for managing the working time of employees in a zone designated as dangerous. At the same time, it could eliminate the need to use personal dosimeters that do not accurately assess actual exposure to noise. The proposed method allows us to estimate the uncertainty assessment of human exposure to noise. Moreover, a large part of the solution is based on tools that do not require incurring licensing costs. The system is about to keep the simulation data of sound level distribution (acoustic maps) and time location of the employee in the database. The concept assumes the unification of a data storage system so that it could be possible to present it in any GIS system.
\end{abstract}

Keywords: database, environmental noise, industrial noise, GIS, acoustic maps

\section{Introduction}

Machines and devices that perform technological processes are the main noise sources in a work environment. Time limits in which the employee may be subjected to work environment noise are precisely defined by standards (PN-N-01307 Noise: Noise limit values in the workplace; requirements for measurement). This is a very important issue to ensure safe working conditions $[1,2]$. At the same time, it could cause some logistical complications, such as the need to reduce work-time or the strict planning of scheduling changes. Therefore, it would be advantageous

*e-mail: bborkow@agh.edu.pl to develop a precise solution that would enable the reduction of financial losses, better management, and sufficient employee protection $[3,4]$.

Exceeding permissible sound levels in the workplace can result in undesired adverse impacts on the human body. Knowledge of the parameters of noise occurring in the work environment is the basis not only for risk assessment, but most of all allows us to take action to counter these effects.

Noise in a work environment is characterized by:

- The level of noise exposure for an 8-hour workday with a corresponding daily exposure or level of noise exposure for a week of work with corresponding weekly exposure (particularly in the case of noise affecting the human body in an unequal manner on a daily basis). 
- The maximum A-weighting sound level.

- The peak C-weighting sound level.

The level of noise exposure is referring to an 8-hour workday. Equivalent A-weighting noise level is the value used regarding the assessment of exposure to time-varying noise. This value is treated as an A-weighting sound level of a stationary noise that works for the same time as the noise of varying sound pressure levels. The peak C-weighting sound level is the maximum value of the instantaneous value of C-weighting sound level. These values are used to evaluate short-term and impulse noises with high levels. The specified values of noise are obligatory for all workers. In practice, it often happens that an employee is subjected to different levels of noise exposure while performing normal activities in a production hall.

\section{Legal Basis: the Obligations of Employers to Reduce Workers' Exposure to Noise}

A whole range of requirements for worker health protection refers in particular to employers (requiring them to counteract harmful effects) and is included in the Regulation of the Minister of Economy and Labour of 5 August 2005 on health and safety at work related to exposure to noise or vibration (J. Laws 2005.157.1318).

In this article the authors mainly focus on the impact of noise on the employee.

On the basis of the results of the measurement of noise, the employer is required to assess the risk arising from exposure of workers to noise resulting from the features of the workplace and with the resources or work processes use in the specific conditions. This evaluation can be done in two ways:

- Doing the measurements at the workplace in accordance with the standard (PN-ISO 9612: 2004 Acoustics; guidelines for the measurement and assessment of noise exposure in the workplace) lasting the full number of hours according to the shifts cycle; precise sound level meters are used for this purpose (PN-79/T-06460 Sound Level Meters).

- Performing an assessment on the basis of a personal dosimeter; the noise dosimeter is a personal meter of exposure to noise that complies with the requirements of PN-EN 61252 standard; it is designed to measure the dose of noise that the employee receives within a specified working time.
Based on these observations and the following formula, we can determine work time at the workplace:

$$
L_{E X, 8 h}=L_{\text {Aeqs } r}+10 \log _{10}\left(\frac{T_{e}}{28800}\right)
$$

...where $L_{E X, 8 h}$ is the level of daily exposure to workplace normalized to eight hours, in $\mathrm{dB} ; L_{\text {Aeqs }}$ is the average noise level, in $\mathrm{dB}$; and $T_{e}$ is the effective time of exposure.

[5] presents exemplary results with measurements using a sound level meter (Table 1) and a dosimeter for five employees (Table 2).

The presented example illustrates a situation when at several workplaces there are significant noise overruns in relation to the limit of $85 \mathrm{~dB}$. Much more accurate information was obtained in the course of the measurement with the use of a dosimeter. By analyzing both cases, the conclusion is that these types of measurements are timeconsuming and costly.

Also, when we would like to analyze a large number of employees in relation not to just one shift but to continuous monitoring, the cost would be greatly increased. Therefore, we propose a different approach based on acoustic maps created in an application to simulate the acoustic field distribution in the analyzed area.

\section{The Proposal Solution}

Existing evaluation methods of noise exposure do not allow for an assessment of the dynamic changes in the work environment, as has been shown in the section above. The evaluation is done once and is valid for a period of one year. It is often referenced is the worst variant, which is the effect of noise on the human body in the case of the acoustic impact on all sources. The question is: what if you turn off a given section of the production or launch a new machine?

According to the regulation of the minister, the noise measurements should be performed:

- Not later than 30 days from the date of commencement of activity (results of tests and measurements shall be kept for a period of three years from the date of the last entry).

- At least once a year, when the results of recently performed measurement of quantities describing the

Table 1. Noise level measurements for each workplace at a coal mine processing plant (measurements with the use of a sound level meter).

\begin{tabular}{|c|c|c|c|}
\hline Work station & $\begin{array}{c}\text { Daily Exposure Level } \\
L_{E X, 8 h}[d B]\end{array}$ & $\begin{array}{c}\text { Noise level overruns } \\
L_{E X, 8 h}[d B]\end{array}$ & $\begin{array}{c}\text { Permissible operating, } \\
{[\mathrm{min}]}\end{array}$ \\
\hline feed hopper & 97.3 & 12.3 & 28 \\
\hline feeder & 95.4 & 10.4 & 74 \\
\hline conveyor drive No. 1 & 92.9 & 7.9 & 11 \\
\hline car-dump No. 1 & 101.3 & 16.3 & 12 \\
\hline car-dump 16m & 101.2 & 16.2 & 77 \\
\hline
\end{tabular}


Table 2. Noise level measurements for each workplace at a coal mine processing plant (measurements with the use of dosimeter).

\begin{tabular}{|c|c|c|c|}
\hline Worker & $\begin{array}{c}\text { Daily Exposure Level } \\
L_{E X, s h}[d B]\end{array}$ & $\begin{array}{c}\text { Noise level overruns } \\
L_{E X, s h}[d B]\end{array}$ & $\begin{array}{c}\text { Permissible operating, } \\
{[\mathrm{min}]}\end{array}$ \\
\hline 1 & 92.8 & 7.8 & 79 \\
\hline 2 & 92.2 & 7.2 & 91 \\
\hline 3 & 86.4 & 1.4 & 77 \\
\hline 4 & 88.0 & 3.0 & 202 \\
\hline 5 (nightshift) & 87.0 & 2.0 & 308 \\
\hline
\end{tabular}

noise has shown that at least one of them exceeds 0.5 of threshold limit value (TLV).

- At least once every two years when the results of recently performed measurement of quantities describing the noise has shown that at least one of them exceeds $0.2 \mathrm{TLV}$.

- In each case of changes in technical equipment, technological process, or work conditions that could have an impact on the level of emissions or exposure to noise. Occupational risk assessment should be documented and made whenever there have been changes in the conditions of work or if there is a need to show the results of the prophylactic medical examination.

Therefore, an interesting alternative would be the possibility of a more accurate assessment of worker exposure to noise due to the dynamic change of the distribution of the acoustic field in which he or she is located. The solution can be a method that takes into account a shift in the employee's place of residence during the shift without the need of equipping each individually employee with a dosimeter. In addition, an interesting variant would be the possibility of real-time evaluation of the real amount of time of worker exposure to noise on the basis of correlations resulting from:

- A dynamic creation of maps of the distribution of the acoustic field generated on the basis of the sound power of individual sound sources.

- A registration of presence of an employee in the workplace and his motion on a given area.

- Correlation of information in time and space in relation to maps of acoustic field distribution.

This solution allows for the observation of nonstop monitoring. It allows for the possibility of better understanding the impact of the acoustic phenomena on humans in the workplace. Implementation allows for continuous observation of environmental conditions, at the same time reducing the cost of obligatory tests in the workplace. It also allows for eliminating some errors caused by, e.g., leaving a dosimeter in the zone of elevated sound levels. The final cost of the system is minimized by using freely available software under the terms of GNU General Public License (GPL) [6].

\section{Implementation}

On the basis of these general requirements, the authors have attempted to create a system of dynamic evaluation of worker exposure to noise. For this purpose the implementation of sequential steps are listed:

- Creating a computational model of an industrial hall having representation in reality (e.g., the educational hall of the University of Science and Technology), which is necessary to generate the different variants of the acoustic field distribution in a closed area.

- Generating maps of acoustic field distributions for all the options of operating sound sources.

- Simulation of the movement of workers in the production hall.

- Indications of work options for easy identification of the type of acoustic risk.

- A database system design for the registration of key parameters in assessing exposure to noise.

- A study of the possibility of using the GIS systems for the demonstration phase of observation results [7].

- Searching algorithms for risk assessment on the basis of the correlation of the collected data.

- Compare results with the existing methods, which will necessitate taking acoustic measurements in the workplace.

The final step will be to examine of the possibility of using the resultant tool in the case of the impact of other risks on the human body, e.g., vibrations.

\section{Stage One: Calculation Model}

The creation of an industrial hall calculation model (Fig. 1) is necessary in order to generate the different variants of the acoustic field distribution in a closed area, understood as different variants of operation of machines. In the future one could introduce no-load operation modes. At this stage, such models are more than sufficient. The authors evaluated the acoustic power of each machine needed to build the model [8]. They gathered the results concerning the dimensions of the hall and the types of reflective surfaces. This information was entered into the SoundPlan7.2 (GmbH; Etzwiesenberg 15; D-71522 Backnang) calculation software [9]. The model has been characterized as follows:

- Hall height $8 \mathrm{~m}$;

- Reflecting surface of walls is a type of lime-cement plaster;

- Partition walls (walls No. 1 and 2) include lime-cement plaster as a type of reflecting surface; 
- Ground-reflecting surface type of concrete covered with PVC;

- Ceiling-reflecting surface type of lime-cement plaster;

- Three lathes: sound power of lathe [10] Nos. 1 and No. 2 is $104 \mathrm{~dB}$ and lathe No. 3 is $105 \mathrm{~dB}$;

- Two milling machines [10] each of sound power of $101 \mathrm{~dB}$;

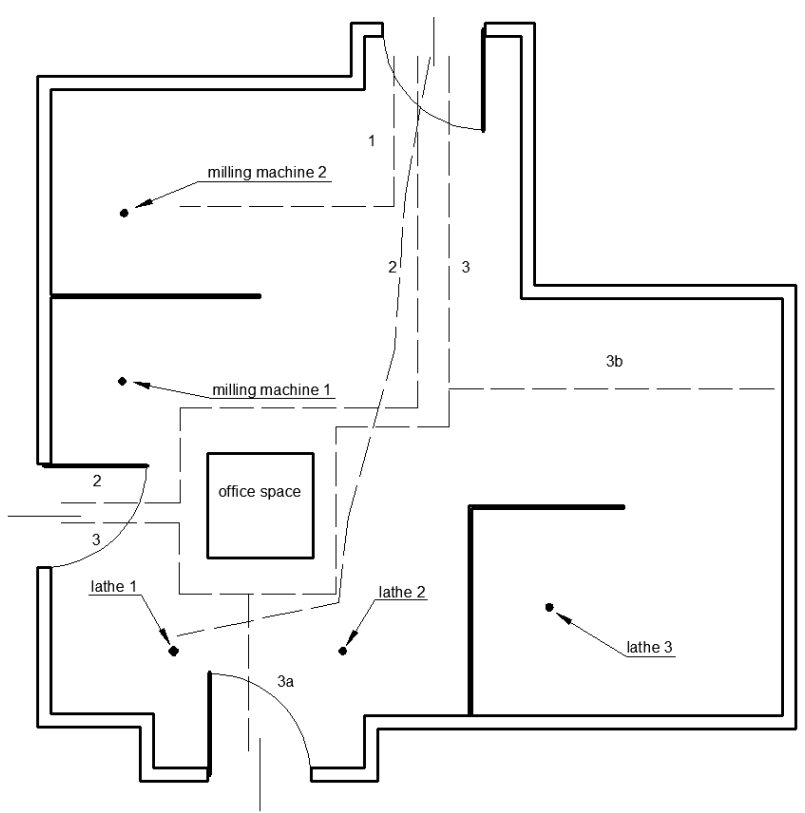

Fig. 1. Industrial hall model.

Table 3. Variants of machine operation in the production hall (X: the machine is running; 0 : the machine is switched off).

\begin{tabular}{|c|c|c|c|c|c|}
\hline No. & Lathe 1 & Lathe 2 & Lathe 3 & $\begin{array}{c}\text { Milling } \\
\text { machine } \\
1\end{array}$ & $\begin{array}{c}\text { Milling } \\
\text { machine } \\
2\end{array}$ \\
\hline 1 & $\mathrm{X}$ & $X$ & $X$ & $X$ & $X$ \\
\hline 2 & 0 & $X$ & $X$ & $X$ & $X$ \\
\hline 3 & $\mathrm{X}$ & 0 & $\mathrm{X}$ & $X$ & $\mathrm{X}$ \\
\hline 4 & $\mathrm{X}$ & $\mathrm{X}$ & 0 & X & $\mathrm{X}$ \\
\hline 5 & $X$ & 0 & 0 & 0 & 0 \\
\hline$\ldots$ & $\ldots$ & $\ldots$ & $\ldots$ & $\ldots$ & $\ldots$ \\
\hline 9 & 0 & 0 & 0 & 0 & $\mathrm{X}$ \\
\hline 10 & $\mathrm{X}$ & $\mathrm{X}$ & 0 & 0 & 0 \\
\hline 11 & 0 & $X$ & $X$ & 0 & 0 \\
\hline$\ldots$ & $\ldots$ & $\ldots$ & $\ldots$ & $\ldots$ & $\ldots$ \\
\hline 14 & $X$ & $X$ & $X$ & 0 & 0 \\
\hline$\ldots$ & $\ldots$ & $\ldots$ & $\ldots$ & $\ldots$ & $\ldots$ \\
\hline 17 & 0 & 0 & $X$ & $X$ & $X$ \\
\hline$\ldots$ & $\ldots$ & $\ldots$ & $\ldots$ & $\ldots$ & $\ldots$ \\
\hline $\begin{array}{c}\mathrm{n}- \\
\text { background }\end{array}$ & 0 & 0 & 0 & 0 & 0 \\
\hline
\end{tabular}

Lines 1, 2, 3, 3a, and 3b illustrate the communication paths marked out in the production hall. In order to show and describe the operational variants of machines, information has been collected in Table 3 .

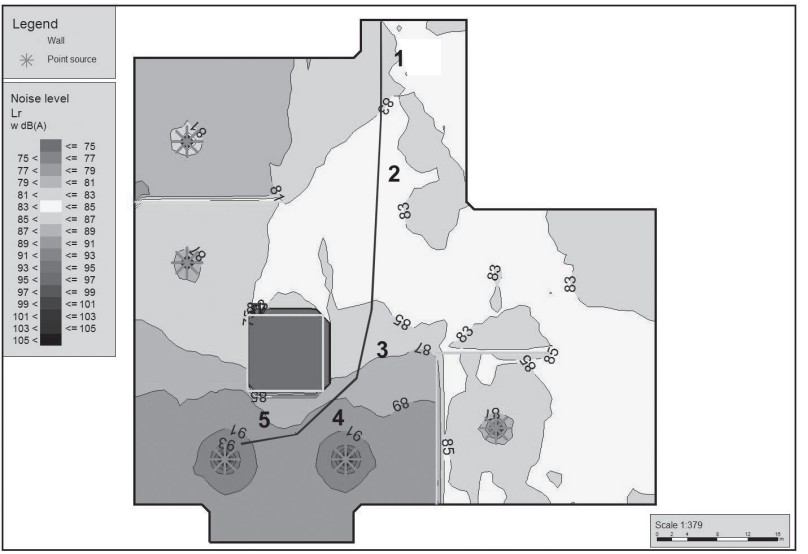

Fig. 2. The distribution of the acoustic field - variant 1. Using this solution one can obtain complete information about the area in which the employee is located and his or her logistics over the course of a normal working day. Markings 1-5 are indexes of sections of sample trajectory.

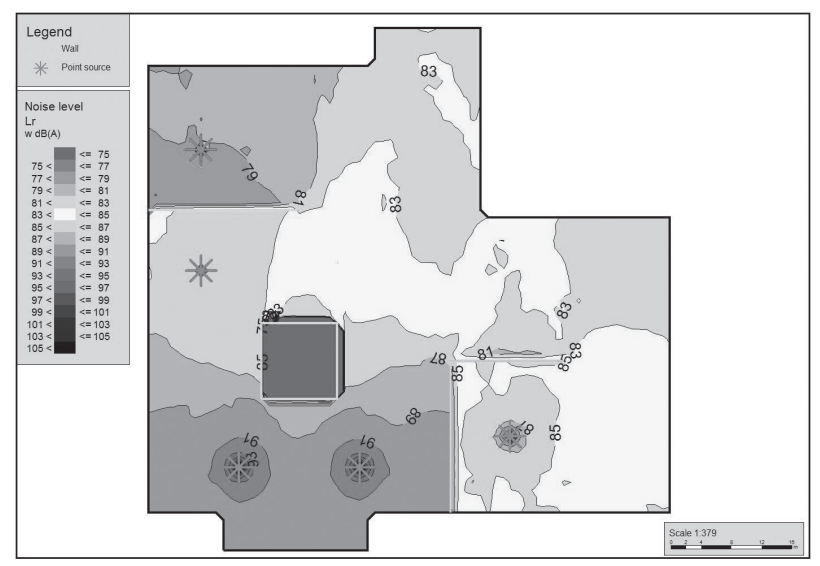

Fig. 3. Distribution of the acoustic field - variant 14 .

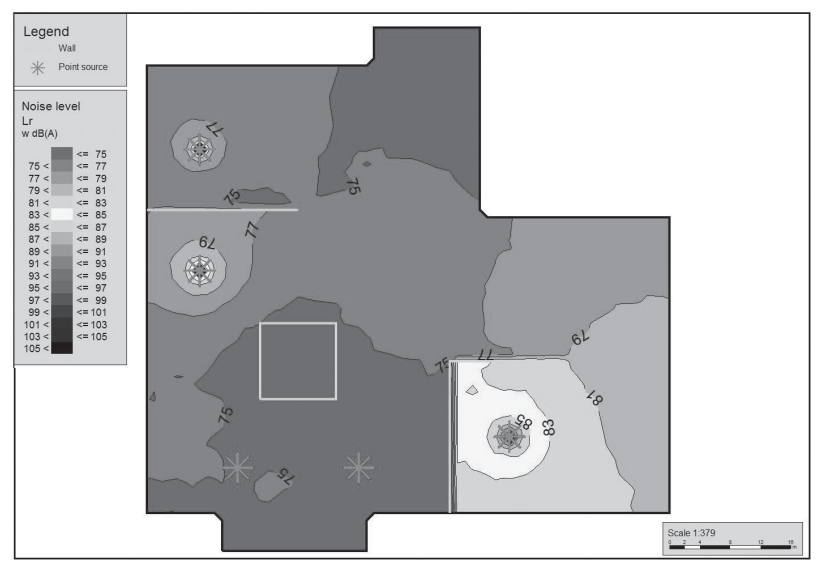

Fig. 4. Distribution of the acoustic field - variant 17. 
Sound field distribution maps (Figs 2-4) were generated for all variants as in Table 3. Currently, maps are generated for an altitude of $1.7 \mathrm{~m}$ (above floor level). In the next stage of the research, maps will be generated for various altitudes.

In order to illustrate the performance of the system, the impact of the noise on the employee was stated based on the theoretical model. In calculations the exemplary trajectory (Fig. 2) was crossed 40 times, the 15-minute break and the 17th variant of combination of machines at work were taken into account. Exemplary results of modelled noise impact on the employee are presented in Table 4. On the basis of the section length (as can be seen in Fig. 2) and time the employee needs to walk it, one can estimate equivalent sound level exposure in this section. These results obtained using the presented method should be compared with a real model. At this stage of work, it can be assumed that approximate results will be obtained with a dosimeter measurement. The example as well as literature reports [11] show great impact of short-level disturbances on long-term indexes.

\section{Determine the Position of the Employee}

Because the idea of this project is to evaluate worker exposure to pollution available in the workplace (in this case noise) without the use of personal dosimeters, it becomes necessary to appoint the exposure time of a worker to the medium. As shown in Fig. 1, the employee may move around the various passageways, such walking from door No. 1 to door No. 2, and has a choice of two trajectories, and thus moving with the same speed will be exposed to different levels of impact. Accordingly, it is necessary to record the history of the location of a worker in the area over the course of the shift. The authors would like to attempt to exploit the RTLS system of the Ubisense Company [12].

The system of Location and Identification in real time (RTLS) allows accurate and reliable determination of the

Table 4. Exemplary results of modelled noise impact on employees.

\begin{tabular}{|c|c|c|c|}
\hline No. & Route length $[\mathrm{m}]$ & $T_{m}[\mathrm{~s}]$ & $L_{\text {AeqTm }}[\mathrm{dB}]$ \\
\hline 1 & 12 & 632 & 81 \\
\hline 2 & 23 & 1211 & 83 \\
\hline 3 & 8 & 406 & 85 \\
\hline 4 & 5 & 288 & 87 \\
\hline 5 & 13 & 659 & 89 \\
\hline 6 & At the workplace & 23904 & 91 \\
\hline 7 & Break & 900 & 60 \\
\hline
\end{tabular}

$T_{m}$ is exposure time, $L_{\text {AeqT }}$ is equivalent sound level exposure: the time of exposure to noise $(\mathrm{dB})$; the total level of exposure to noise is $90.3 \mathrm{~dB}$. position of objects in 2D and 3D spaces, in real time, and, most importantly, the system is dedicated to the closed areas. Its advantages are as follows:

- Accuracy of $15 \mathrm{~cm}$, a delay of $75 \mathrm{~ms}$.

- Work in closed areas and open spaces.

- Reliable operation in an industrial environment.

- The ability to identify and locate any objects, in particular people.

- Small size of the labels used for the location of objects.

\section{The Database System}

At this stage, it becomes necessary to correlate other information from the maps of sound level generated on the basis of observations (measurements) and the location data of the employee. For this purpose it is necessary to use database systems for collecting, processing and exposing data. Additionally, one must use the dedicated application of maps and of GEO data presentation. For this purpose the authors of this paper would like to apply the GrassGeographic Resources Analysis Support System (the GIS class system) [13], which allows for analysis and synthesis of maps. It has extensive tools for analyzing raster and vector layers. It also enables vector network analysis. A valuable feature of this system is the ability to interact with database management systems, including MySQL and PostgreSQL. Part of the calculations related to the determination of worker exposure to noise will be carried out using the GRASS system $[6,13]$. In previous works of the Authors, the GRASS program was used, inter alia, to generate acoustic maps. $[14,15]$ present the possibility of the using GIS to generate dynamic noise maps. In this paper, noise maps generated from influence maps and acoustic power of sound sources will permit assessment of worker exposure to noise during operation. By using layers it will be possible to present the results in a meaningful way.

PostgreSQL is an object-relational database management system. According to the manufacturer's declaration it is the most advanced database management system issued with an open source code. A valuable feature of this system is an extension called the PostGIS that allows the use of PostgreSQL as a database of geographical data. With this extension using PostgreSQL it can also perform certain operations on geographical data.

\section{Summary and Conclusions}

Our paper considers the possible use of IT tools to evaluate worker exposure to noise and other pollution in the workplace. These tools have been used more globally as strategic noise maps as well as systems for spatial information management. The authors of the article present the concept of an alternative method for assessing - different from those used previously - and present the advantages which, inter alia, are:

- Accurate assessment of worker exposure to pollution of the working environment. 
- The possibility of precise planning of working time load in adverse conditions.

- The ability to analyze communication routes in production halls.

- Clear presentation of the results.

- Exposure assessment in changing conditions.

The advantage of the proposed system is the constant acquisition of measurement data without personal dosimeter usage. The solution also allows for year-round observation of all employees in the production hall, making it possible to address the influence of several pollutants.

The final effect will be to develop a universal algorithm for risk assessment of the example of noise pollution, but with the ability to adapt to other media such as vibration, dust, electromagnetic radiation, etc.

\section{References}

1. MATUSZAK-FLEJSZMAN A. Factors for Improving Environmental Management Systems in Polish Companies According to ISO 14001. Pol. J. of Environ. Stud. 20 (3), 709, 2011.

2. SALEHIN S., NAZMUL ISLAM K.M., ALAM M.S., HOSSAIN M.M., IndustrialNoise Levels in Bangladesh; is Worker Health at Risk?. Pol. J. Environ.Stud. 23 (5), 1719, 2014.

3. FURA B. Improving ISO 14001 Environmental Management Systems. Pol.J. Environ. Stud. 23 (6), 1711, 2013.

4. SMAGOWSKA B. Noise at Workplaces in the Call Center. Archives ofAcoustics 35 (2), 253, 2010.
5. BIAŁY W. Mining of coal: selected problems functioning. Gliwice 2011.

6. GNU General Public License (GPL) http://www.gnu.org/ gnu/manifesto.html. Visited: 22-02-2016.

7. CZAJKA I., OLSZEWSKI R. On the use of open source software to determine the M index in GIS for noise map. Polish Association for Knowledge Management, 40, 98, 2011.

8. PN-EN ISO 11202:2012 Noise emitted by machinery and equipment.2012.

9. SoundPlan - Noise mapping, new noise control concepts, noise planning. http://www.pcplusplus.com.pl/soundplan. html Visited: 01-12-2014.

10. ASMED http://www.asmed.org.pl/dla-lekarzy/artykuly/140halas-w-srodowisku-pracy Visited: 24-11-2014

11. GAJARDO C.P., MORILLAS J.M.B., ESCOBAR V.G., VÍLCHEZ-GÓMEZ R., GOZALO G.R., Effects of Singular Noisy Events on Long-Term Environmental Noise Measurements, Pol. J. Environ. Stud. 23 (6), 2007, 2014.

12. RTLS - Real-time location systems -http://www.astec.net/pl/ rtls/przeglad.html Visited: 22-11-2014.

13. GRASS Geographic Resources Analysis Support Systemhttp://grass.osgeo.org/ Visited: 01-12-2014

14. SUDER-DĘBSKA K., CZAJKA I., GOŁAŚ A., The identification of the power of sound sources in the presence of the incomplete information regarding their location. Progress acoustics, Eds. L. Leniowska, A. Brański, Polish Acoust. Soc., Rzeszów OSA symposium series 225, 2013.

15. CZAJKA I., SUDER-DĘBSKA K., GOŁAŚ A. The use of the idea of smart acoustics to acoustic climate management Archives of Acoustics, 37 (3), 374, 2012. 